\title{
ELECTRON MICROSCOPY FINDINGS ON AN INTRAOCULAR LENS IN THE UVEITIS, GLAUCOMA, HYPHAEMA SYNDROME
}

\author{
R. H. Y. ASARIA ${ }^{1}$, J. F. SALMON ${ }^{1}$, A. R. SKINNER ${ }^{2}$, D. J. P. FERGUSON ${ }^{2}$ and B. McDONALD ${ }^{3}$ \\ Oxford
}

\begin{abstract}
SUMMARY
Purpose: To report the electron microscopic findings on an explanted intraocular lens in a patient with the uveitis, glaucoma, hyphaema syndrome.

Methods: Scanning and transmission electron microscopy were undertaken on a coccoon of cellular material from the tip of the intraocular lens haptic.

Results: Scanning electron micrographs showed densely packed coccoid-like structures on the haptic surface. By transmission electron microscopy these structures proved to be melanosomes.

Conclusions: The scanning electron micrographs described in this report are similar to those reported in patients with chronic post-operative uveitis, but to our knowledge have not been shown before in association with the uveitis, glaucoma, hyphaema syndrome. Transmission electron microscopy determined that the coccoid-like structures were melanosomes. The melanosomes are probably derived from damaged pigment epithelial cells or iris stromal melanocytes secondary to recurrent chafing of the haptic against the posterior surface of the iris.
\end{abstract}

The uveitis, glaucoma, hyphaema syndrome (UGH syndrome) was originally described by Ellingson in $1977,{ }^{1}$ as a late complication of intraocular chafing by poorly finished first-generation anterior chamber intraocular lens (IOL) implants. With the advent of modern one-piece PMMA posterior chamber IOLs the syndrome is less often encountered, particularly if the IOL is placed within the capsular bag. ${ }^{2}$ In this report we describe a patient who presented 9 years after implantation of a posterior chamber IOL with

From: ${ }^{1}$ Oxford Eye Hospital, Walton Street, Oxford $;{ }^{2}$ Electron Microscopy Unit, Department of Cellular Pathology, John Radcliffe Hospital, Headington, Oxford; ${ }^{3}$ MRC Schizophrenia Research Group, Department of Neuropathology, Radcliffe Infirmary National Health Service Trust, Woodstock Road, Oxford, UK.

Correspondence to: Mr J. F. Salmon, MD, FRCS, FRCOphth, Oxford Eye Hospital, Walton Street, Oxford OX2 6AN, UK. Tel/fax: (+44) 01865224360 characteristic signs of UGH syndrome. The IOL was removed and electron microscopy was undertaken on cellular debris from the tip of one haptic. The findings are unusual and to our knowledge have not previously been described in this syndrome.

\section{CASE REPORT}

In 1983 a 70 -year-old white man with no previous ophthalmic problems underwent an uncomplicated cataract extraction with implantation of a posterior chamber Sinskey IOL in the left eye. The patient was discharged with a best corrected visual acuity of $6 / 5$.

He presented 9 years later with a sudden loss of vision and pain in the same eye. Examination revealed a vision of 'hand movements', an intraocular pressure of $43 \mathrm{mmHg}$, stromal and epithelial corneal oedema and a microscopic hyphaema. The optic disc was normal. There was no sign of pseudoexfoliation syndrome in either eye. Although the eye settled completely on topical corticosteroids and glaucoma treatment, the problem recurred on numerous occasions over a 2-year period and on each occasion settled on topical therapy. Progressive glaucomatous atrophy was demonstrated so the IOL was removed from the ciliary sulcus and was exchanged with a one-piece PMMA posterior chamber lens. No intravitreal antibiotic was given. The explanted lens was immersed in $4 \%$ glutaraldehyde in $0.1 \mathrm{M}$ phosphate buffer solution and processed for scanning electron microscopy. Cellular material was subsequently processed for transmission electron microscopy. The patient has remained asymptomatic with $6 / 5$ vision, an intraocular pressure of less than 20 $\mathrm{mmHg}$ and a stable visual field more than 2 years after surgery.

Initial scanning electron microscopy showed a coccoon of cellular debris on the surface of one haptic tip (Fig. 1). Higher magnification revealed clusters of spherical structures, approximately $1 \mu \mathrm{m}$ 


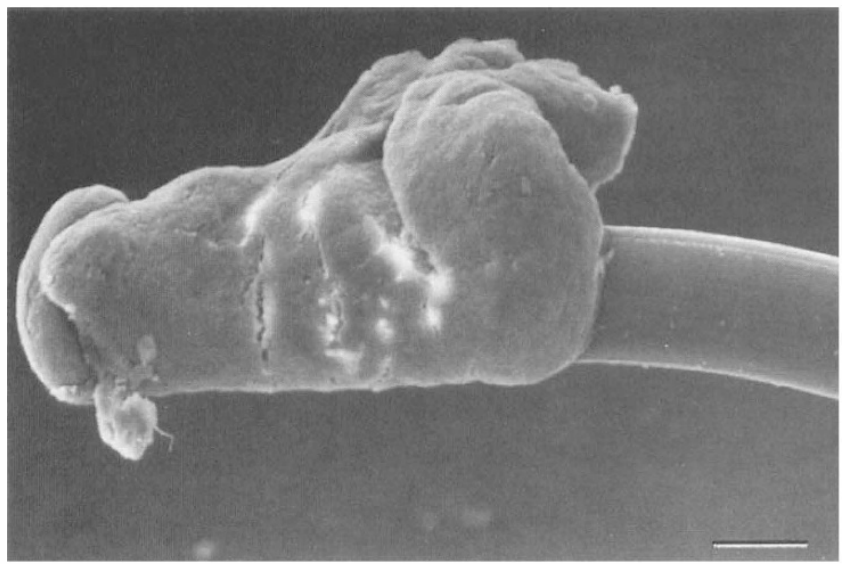

Fig. 1. Scanning electron micrograph showing material attached to the tip of a lens haptic. Scale bar represents $0.1 \mathrm{~mm}$.

in diameter, resembling bacterial cocci (Fig. 2), raising the possibility of low-grade bacterial contamination as a cause of the signs and symptoms in this patient. However, transmission electron microscopy on this material demonstrated that the coccoid structures were densely packed clusters of melanosomes (Fig. 3).

\section{DISCUSSION}

UGH syndrome typically occurs $2-5$ years after surgical implantation of an IOL and so this case is slightly unusual in that symptoms started 9 years after surgery. ${ }^{1,3}$ If the IOL is placed in the ciliary sulcus, vaulting, decentration and excessive movement of the lens may result in a breakdown of the blood-aqueous barrier, with signs of anterior uveitis. ${ }^{4}$ Further intermittent contact with the fragile vascular uveal tissue may then cause chafing, erosion and pigment dispersion, and result in recurrent

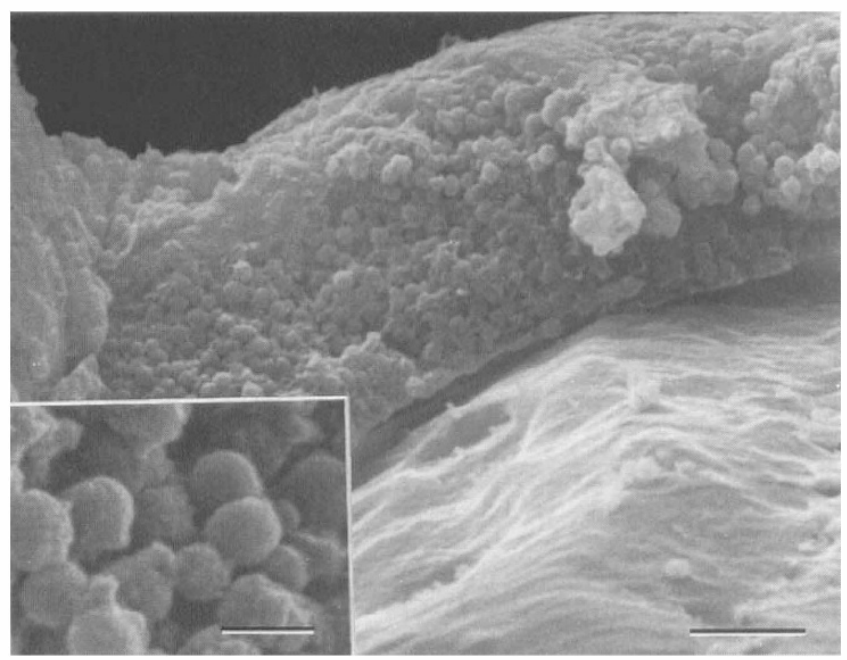

Fig. 2. Details of the surface of the material attached to the haptic tip showing densely packed coccoid-like structures. Scale bar represents $5 \mu \mathrm{m}$. Insert: Enlargement showing uniform spherical structures. Scale bar represents $1 \mu \mathrm{m}$.

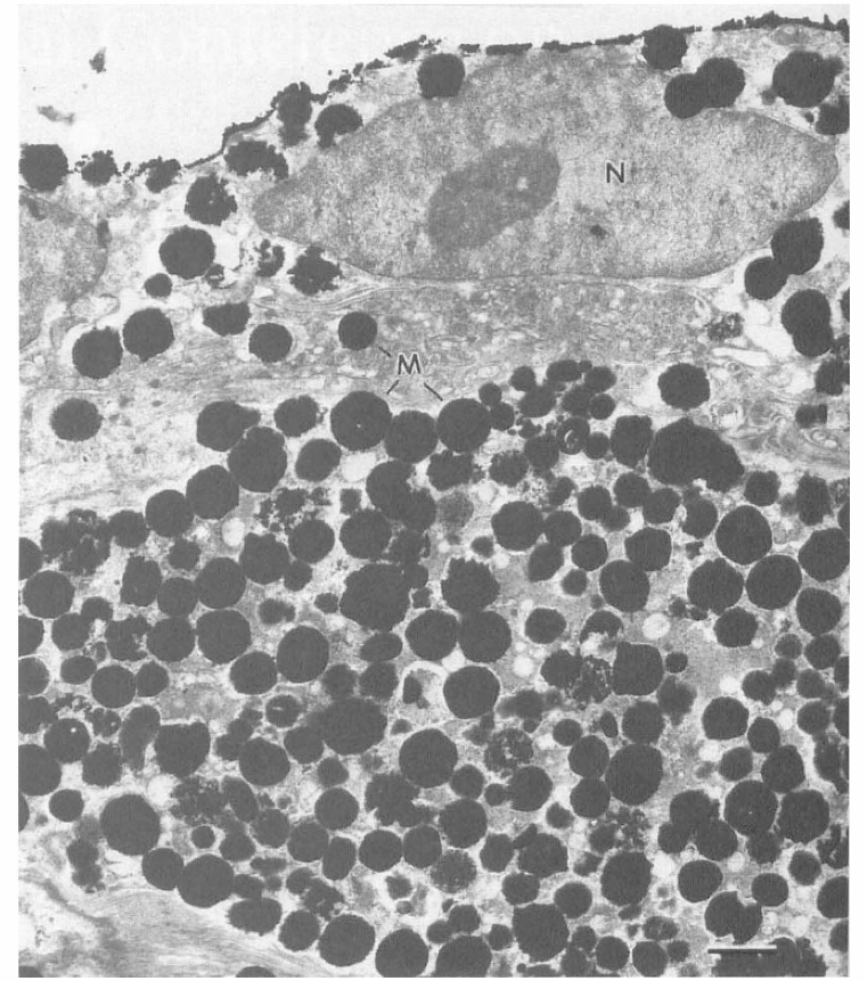

Fig. 3. Transmission electron micrograph through the attached material shown in Figs. 1 and 2 in which degenerate cells containing numerous melanosomes (M) can be seen. $N$, nucleus. Scale bar represents $1 \mu \mathrm{m}$.

episodes of hyphaema, raised intraocular pressure and anterior uveitis. ${ }^{5}$ Raised intraocular pressure occurs secondary to persistent inflammation, pigment dispersion and deposition, or as a result of macrophages containing degraded red blood cells blocking the trabecular meshwork. With time, glaucomatous atrophy and visual field loss may occur.

Other causes of chronic inflammation after IOL implantation have been reported. Whereas early studies described anterior uveitis as a result of a foreign-body reaction to the lens material or to the presence of toxic compound on the lens surface, more recently it has been shown that low-grade chronic inflammation can be caused by relatively avirulent organisms that are sequestrated within the capsular bag. ${ }^{6-11}$ Previous studies have reported the cellular findings on explanted IOLs from patients with chronic uveitis. ${ }^{9-11}$ In the present case scanning electron microscopy revealed coccoid-like structures on the haptic surface suggestive of a low-grade infection of late onset. However, transmission electron microscopy demonstrated conclusively that the spherical structures were melanosomes and not cocci. To our knowledge, these ultrastructural observations have not previously been reported in a patient with UGH syndrome. In this situation, the melanosomes are probably derived from damaged pigment epithelial cells or stromal melanocytes 
secondary to recurrent chafing of the haptic against the posterior aspect of the iris. ${ }^{12}$

In patients with UGH syndrome, topical corticosteroids and medication to reduce the intraocular pressure usually control the intraocular inflammation and intraocular pressure in the short term and bring symptomatic relief. However, when the vision is reduced, or raised intraocular pressure and inflammation cannot be controlled or progressive glaucomatous atrophy is demonstrated, then simple IOL exchange is effective, as demonstrated in this case.

Key words: Uveitis glaucoma hyphaema (UGH) syndrome, Electron microscopy, Intraocular lens implant, Melanosomes.

\section{REFERENCES}

1. Ellingson FT. Complications with the Choyce Mark III anterior chamber lens implant. J Am Intraocular Implant Soc 1977;3:199-201.

2. Apple DJ, Kincaid MC, Mamalis N, Olson R. Posterior chamber lenses. In: Intraocular lenses: evolution, designs, complications and pathology. Baltimore: Williams and Wilkins, 1995:107-67.

3. Apple DJ, Mamalis N, Loftfield K, et al. Complications of intraocular lenses: a historical and histopathological review. Surv Ophthalmol 1984;29:1-54.
4. Miyake K, Asakura M, Kobayashi H. Effect of intraocular lens fixation on the blood-aqueous barrier. Am J Ophthalmol 1984;98:451-5.

5. Miyake S. Pseudophakic posterior iris chaffing syndrome. J Cataract Refract Surg 1986;12:252-6.

6. Apple DJ, Mamalis N, Brady SE, et al. Biocompatibility of implant materials: a review and scanning electron microscopic study. J Am Intraocul Implant Soc 1984;10:53-6.

7. Sievers H, von Domarus D. Foreign-body reaction against intraocular lenses. Am J Ophthalmol 1984;97: 743-51.

8. Ficker L, Meredith TA, Wilson LA, et al. Chronic bacterial endophthalmitis. Am J Ophthalmol 1987;103: $745-8$.

9. Cusumano A, Busin M, Spitznas M. Is chronic intraocular inflammation after lens implantation of bacterial origin? Ophthalmology 1991;98:1703-10.

10. Busin M, Cusumano A, Spitznas M. Intraocular lens removal from eyes with chronic low grade endophthalmitis. J Cataract Refract Surg 1995;21:679-84.

11. McLaughlin-Borlace LA, Morlet N, Barber P, Dart JKG. A scanning electron microscope study of the presence of bacterial biofilm on intraocular implants. Proc R Microsc Soc 1996;31:133.

12. Ghadially FN. Ultrastructural pathology of the cell and matrix. 2nd ed. London: Butterworth, 1982:616-8. 